\title{
Comparison of two palliative radiotherapy schedules of radiotherapy in locally advanced head and neck
} \section{cancer}

\begin{abstract}
Background and Aims: Head and neck cancer accounts for $4.8 \%$ of all cancers globally and $13.9 \%$ of all cancers in India. ${ }^{1}$ In Indian setting, more than $70 \%$ patients present in locally advanced stage and with poor general condition and are suitable candidates for palliative radiotherapy. The present prospective, randomized study was planned to comparatively evaluate the efficacy, tolerability and toxicity of two schedules of palliative radiotherapy in patients of locally advanced head \& neck cancer (LAHNC).
\end{abstract}

Methods: The present study was carried out on histopathological proven and inoperable 60-patients of LAHNC. Patients in group I received total external radiation dose of 40Gy, $4 \mathrm{~Gy} /$ fraction, and 2 fractions a week for 5 weeks. Group II patients received 20Gy in 5 fractions in 5 days followed by 3 week gap followed by $20 \mathrm{~Gy}$ in 5 fractions in 5 days. The groups were compared in terms of local tumor control and adverse effects of radiation.

Results: All patients were of stage IV and $83 \%$ had nodal involvement. At the end of treatment for local disease, complete response (CR) in group I was better than group II (13.2\% vs 3.3\%) and complete nodal response was seen in $17 \%$ patients in each group. Disease status at 6 months of follow up was $27 \%$ vs $23 \%$ complete tumor response and $30 \%$ vs $24 \%$ complete nodal response in group I and II respectively. Overall no evidence of disease (NED) was seen in $13 \%$ in group I and $17 \%$ in group II. Grade 3 skin radiation reactions were only seen in 1-patient of group II, however, grade 3 mucosal radiation reactions were seen in $20 \%$ patients in group I and $7 \%$ in group II. Seven patients in group I required nasogastric feeding tube as compared to 3-patients in group II. Grade 3 subcutaneous toxicity was equally present in $3 \%$ in each group.

Conclusions: In this study we observed that both the schedules of radiotherapy are equally effective in tumor control and have comparable toxicity profile. Hence, to decrease the patient load in tertiary care institutes, it is recommended to use fractionation schedule with two radiotherapy fractions per week.

Keywords: head and neck cancer, palliative radiotherapy, early radiation reaction, late radiation toxicity, tumor control, LAHNC
Volume 9 Issue 4 - 2018

Tarun Kumar, Anil Kumar Dhull, Rajeev Atri, Rakesh Dhankhar,Vivek Kaushal

'Department of Radiation Oncology, Post Graduate Institute of Medical Sciences, India

Correspondence: Anil Kumar Dhull, Radiation Oncologist, Department of Radiation Oncology, Post Graduate Institute of Medical Sciences, PO Box 100, GPO Rohtak-I2400I, Haryana, India, Fax+9I-126-22-99999, Email anilkdhull@gmail.com

Received: June 06, 2018 | Published: July 03, 2018
Abbreviations: EBRT, external beam radiation therapy; LAHNC, locally advanced head and neck cancer; HNC, head \& neck cancer; ICD, international classification of diseases; SGOT, serum glutamic-oxaloacetic transaminase; SGPT, serum glutamicpyruvic transaminase; NED, no evidence of disease; CR, complete response; PR, partial response; AJCC, american joint committee on cancer; RTOG, radiation therapy oncology group; SWOG, south west oncology group; QOL, quality of life

\section{Introduction}

Majority of patients of head and neck cancer present in locally advanced stage, and thus, local failure rates are as high as $50-70 \% .^{1-3}$ Radiotherapy alone or in combination with chemotherapy is the standard non-surgical therapy for LAHNC. The goal of treatment in these patients is to achieve prompt relief of distressing symptoms. There have been some reports on the use of hypofractionated radiotherapy for palliation in LAHNC but many are methodologically flawed, with limited or no toxicity data and no assessment of response of tumor to palliative radiotherapy. ${ }^{4}$ The present prospective, randomized study was planned to comparatively evaluate the efficacy, tolerability and toxicity of two schedules of palliative radiotherapy in LAHNC.

\section{Material and methods}

The present study was carried out on histopathologically proven and inoperable 60 patients of LAHNC. These patients were randomly divided in two groups of 30 patients each by draw of lots. The patients were staged according to AJCC 2010 TNM staging system. All patients in group I (study group) received total radiation dose of 40Gy, $4 \mathrm{~Gy} /$ fraction, 2 fractions a week for 5 weeks. Group II patients (control group) received $20 \mathrm{~Gy}$ in 5 fractions in 5 days followed by 3 weeks gap followed by $20 \mathrm{~Gy}$ in 5 fractions in 5 days. Tumor response (both primary and nodal response) was assessed by WHO response criteria either clinically or if needed, radiologically. ${ }^{5}$ Radiation reactions were assessed by Radiation Therapy Oncology Group (RTOG) criteria. ${ }^{6}$ Both tumor response and radiation reactions were compared at the end of treatment and 6month follow-up. 


\section{Results and discussion}

The male to female ratio was 11:1 in both the groups. Most of the patients were of rural background (76\%) and chronic smokers $(88 \%)$. Fifty two percent patients were both chronic smokers as well as alcoholics. Most of the primary lesions were ulcer proliferative (53\%) and most common histopathology was moderately differentiated squamous cell carcinoma (80\%). Throat pain was most common chief complaint presenting in $37 \%$ patients. Most common primary site involved was base of tongue in $40 \%$ of patients. All patients were of stage IV and $83 \%$ had nodal involvement. At the end of treatment for local disease, complete response (CR) in group I was better than group II (13\% vs 3\%). Partial response (PR) at the end of treatment was more in group II (84\%) compared to $74 \%$ in group I. Each group had equal patients (13\%) with no response in local disease at the end of treatment. At the end of treatment complete nodal response was seen in $17 \%$ patients in each group and partial nodal response was slightly better in group II $(67 \%)$ as compared to $60 \%$ in group I.

At the end of treatment, grade 2 skin reactions were $20 \%$ and $24 \%$ in group I and II respectively while grade 3 skin reactions was only seen in 1 patient of group II. Grade 2 mucosal reactions were $37 \%$ and $23 \%$ in group I and II respectively while grade 3 mucosal reactions was seen in $20 \%$ patients in group I and $7 \%$ in group II.

Grade 2 pharyngeal complications were 53\% vs $57 \%$ and esophageal complications were $23 \%$ vs $10 \%$ in group I and II respectively. Seven patients in group I required nasogastric feeding tube as compared to three patients in group II. According to South West Oncology Group (SWOG) criteria, 7 patients (23\%) in group I experienced grade 2 weight loss over the course of treatment compared to 6 patients $(20 \%)$ in group II.

Disease status at 6 months of follow up was noted as $26 \%$ vs $23 \%$ complete tumor response and $30 \%$ vs $23 \%$ complete nodal response in group I and II respectively. Overall no evidence of disease (NED) was seen in $13 \%$ in group I and 17\% in group II (Table 1). Grade 1 late radiation skin toxicity was higher in group II ( $53 \%$ vs $67 \%$ ), however, grade 2 late radiation skin toxicity was higher in group I than group II (33\% vs $13 \%)$. Grade 1 late radiation subcutaneous toxicity was higher in group I ( $30 \%$ vs $17 \%)$ but grade 2 was higher in group II (57\% vs $63 \%$ ). Grade 3 subcutaneous toxicity was equally present in $3 \%$ in each group. Grade 1 late radiation mucosal toxicity was higher in group II (33\% vs $43 \%)$ whereas grade 2 was higher in group I $(57 \%)$ as compared to $47 \%$ in group II (Table 2 ).

In third world countries as is India, incidence of LAHNC is quite high. According to hospital-based retrospective study of all patients in 12 years study in Regional Cancer Centre, PGIMS Rohtak from the year 2001 to 2012, Head and neck cancer comprises around $37.8 \%$ of all malignancies. ${ }^{6}$ As most of the cases are in advanced stage with poor general condition and the distressing symptoms warrants palliation of the symptoms with radiotherapy. Improvement in symptoms along with QOL is an important aspect of palliation. As there is no standard schedule for palliative radiotherapy in LAHNC various palliative schedules have been tried ranging from 20 Gy in 5 fractions to 40 50 Gy in 10 to 15 fractions which had variable tumor response and radiation reactions. ${ }^{7,8}$
Similar studies had shown that in LAHNC, palliative radiotherapy can achieve $70-80 \%$ local tumor control at the end of treatment and $20-30 \%$ patients with no clinical disease with less than $10 \%$ severe late radiation reactions at the end of 6 months follow up. . $^{48-10}$

Table I Disease status at the end of six month follow up

\begin{tabular}{llll}
\hline Tumor & Group I & Group II & P value \\
\hline Complete response(CR) & $08(26.4 \%)$ & $07(23.4 \%)$ & 0.766 \\
Partial response(PR) & II(36.3\%) & $12(40 \%)$ & 0.592 \\
Recurrence & $08(26.4 \%)$ & $09(30 \%)$ & 0.744 \\
Death & $03(10.0 \%)$ & $02(6.6 \%)$ & 0.389 \\
Nodal & & & \\
Complete response(CR) & $09(30 \%)$ & $07(23.3 \%)$ & 0.559 \\
Partial response(PR) & $05(16.6 \%)$ & $08(26.7 \%)$ & 0.347 \\
Recurrence & $08(26.7 \%)$ & $08(26.7 \%)$ & 1.00 \\
Death & $03(10.0 \%)$ & $02(6.6 \%)$ & 0.389 \\
No lymph node(N0) palpable & $05(16.6 \%)$ & $05(16.6 \%)$ & 1.00 \\
at time of presentation & & & \\
Overall & & & \\
No evidence of disease(NED) & $04(13.3 \%)$ & $05(16.6 \%)$ & 0.718 \\
Partial response(PR) & $14(46.7 \%)$ & $14(46.7 \%)$ & 0.347 \\
Recurrence & $09(30.0 \%)$ & $09(30.0 \%)$ & 1.00 \\
Death & $03(10.0 \%)$ & $02(6.7 \%)$ & 0.64 \\
\hline
\end{tabular}

Table 2 Late radiation reactions at end of six month follow up

\begin{tabular}{llll}
\hline Cutaneous & Group I & Group II & P value \\
\hline Grade 0 & $03(10 \%)$ & $06(20 \%)$ & 0.278 \\
Grade I & $16(53.4 \%)$ & $20(66.7 \%)$ & 0.292 \\
Grade 2 & $10(33.3 \%)$ & $04(13.3 \%)$ & 0.067 \\
Grade 3 & $01(3.3 \%)$ & $00(0 \%)$ & None \\
Subcutaneous & & & \\
Grade 0 & $03(10 \%)$ & $05(17 \%)$ & 0.448 \\
Grade I & $09(30 \%)$ & $05(17 \%)$ & 0.222 \\
Grade 2 & $17(56.7 \%)$ & $19(62.7 \%)$ & 0.598 \\
Grade 3 & $01(3.3 \%)$ & $01(3.3 \%)$ & 1.00 \\
Mucosal & & & 0.438 \\
Grade 0 & $02(6.7 \%)$ & $03(10 \%)$ & 0.64 \\
Grade I & $11(33 \%)$ & $13(43.3 \%)$ & 0.598 \\
Grade 2 & $17(57 \%)$ & $14(46.7 \%)$ & $0.430 n$ \\
Grade 3 & $01(3.3 \%)$ & $00(0 \%)$ & \\
\hline
\end{tabular}


In this present study complete local response at the end of treatment was better in group I than group II (13.2\% vs 3.3\%). Partial response at the end of treatment was more in group II (84\%) compared to $74 \%$ in group I. Acute grade 3 skin reactions was only seen in 1-patient of group II whereas grade 3 mucosal reactions was seen in $20 \%$ patients in group I and 7\% in group II. Seven patients in group I required nasogastric feeding tube as compared to three patients in group II.
No evidence of disease (NED) was seen in $13 \%$ in group I and $17 \%$ in group II at 6 month of follow up. Grade 3 late radiation skin and mucosal toxicity was higher in group I (3.3\% each) as compared to group II ( $0 \%$ each). Grade 3 subcutaneous toxicity was equally present in $3 \%$ in each group. These results were similar and in accordance to the similar studies done by various authors. A few of those studies and their results are described in Table 3 .

Table 3 Comparison of different studies with disease response, acute and late skin and mucosal reactions

\begin{tabular}{|c|c|c|c|c|c|c|c|c|}
\hline S.No & Reference & $\begin{array}{l}\text { Dose and } \\
\text { fractionation }\end{array}$ & $\begin{array}{l}\text { Disease } \\
\text { response }\end{array}$ & $\begin{array}{l}\text { Acute } \\
\text { grade } \\
3 \text { skin } \\
\text { reactions }\end{array}$ & $\begin{array}{l}\text { Acute } \\
\text { grade } 3 \\
\text { mucosal } \\
\text { reactions }\end{array}$ & $\begin{array}{l}\text { NED status } \\
\text { at the end } \\
\text { of } 6 \text { months }\end{array}$ & $\begin{array}{l}\text { Late grade } 3 \\
\text { skin } \\
\text { radiation } \\
\text { toxicity- skin }\end{array}$ & $\begin{array}{l}\text { Late grade } \\
3 \text { mucosal } \\
\text { radiation } \\
\text { toxicity- } \\
\text { skin }\end{array}$ \\
\hline I & Agarwal et al. ${ }^{10}$ & $\begin{array}{l}40 \text { Gy in } 16 \text { fractions in } \\
3.1 \text { weeks }\end{array}$ & $\begin{array}{l}\text { CR-10\% } \\
\text { PR-63\% }\end{array}$ & $14 \%$ & $63 \%$ & - & - & $9 \%$ \\
\hline \multirow[t]{2}{*}{2} & Das et al. ${ }^{\prime \prime}$ & $\begin{array}{l}40 \mathrm{~Gy} \text { in } 10 \text { fractions in } 5 \\
\text { fractions/week }\end{array}$ & veeks with 2 & $3 \%$ & $18 \%$ & - & - & - \\
\hline & & $\begin{array}{l}\text { I4.8Gy in } 4 \text { fractions } \\
\text { thrice, three } \\
\text { weekly(quad shot) }\end{array}$ & Local control-84\% & $28 \%$ & $36 \%$ & $20 \%$ & $3.30 \%$ & $3.30 \%$ \\
\hline \multirow[t]{2}{*}{3} & Soni et al. ${ }^{4}$ & $\begin{array}{l}50 \mathrm{~Gy} \text { in } 16 \text { fractions in } \\
3.1 \text { weeks }\end{array}$ & Local control-76\% & $44 \%$ & $56 \%$ & $28 \%$ & $6.70 \%$ & $10 \%$ \\
\hline & & $\begin{array}{l}20 \mathrm{~Gy} \text { in } 5 \text { fractions } \\
\text { in } 5 \text { days twice, } \\
\text { three weeks } \\
\text { apart(total } 40 \mathrm{~Gy} / 10 \\
\text { fractions } / 5 \text { weeks) }\end{array}$ & Local control-76\% & $16 \%$ & $24 \%$ & $16 \%$ & - & - \\
\hline 4 & $\begin{array}{l}\text { Kancherla et } \\
\text { al. }{ }^{12}\end{array}$ & $\begin{array}{l}20 \mathrm{~Gy} \text { in } 5 \text { fractions } \\
\text { in } 5 \text { days twice, } \\
\text { two weeks } \\
\text { apart(total } 40 \mathrm{~Gy} / 10 \\
\text { fractions/4weeks) }\end{array}$ & $\begin{array}{l}\text { CR-39\% } \\
\text { PR-33\% }\end{array}$ & $3 \%$ & $6 \%$ & - & - & - \\
\hline \multirow{3}{*}{5} & & $\begin{array}{l}40 G y \text { in } 10 \text { fractions } \\
\text { in } 5 \text { weeks with } \\
2 \text { fractions per } \\
\text { week(group I) }\end{array}$ & $\begin{array}{l}\text { Local tumor } \\
\text { CR-13.2\% } \\
\text { PR-74 }\end{array}$ & $0 \%$ & $20 \%$ & $13 \%$ & $3.30 \%$ & $3.30 \%$ \\
\hline & Present study & $\begin{array}{l}20 \text { Gy in } 5 \text { fractions } \\
\text { in } 5 \text { days twice, three }\end{array}$ & $\begin{array}{l}\text { Local tumor } \\
\text { CR-3.2\% }\end{array}$ & & & & & \\
\hline & & $\begin{array}{l}\text { weeks apart(group } \\
\text { II),(total } 40 \mathrm{~Gy} / 10 \\
\text { fractions/5weeks) }\end{array}$ & PR-84 & $3 \%$ & $7 \%$ & $17 \%$ & $0 \%$ & $0 \%$ \\
\hline
\end{tabular}




\section{Conclusion}

In this study, we observed that both the schedules of radiotherapy are equally effective in tumor control and have comparable toxicity profile. Thus, we conclude that 40 Gy in 10 fractions in 5 weeks either by 2 fractions per week for 5 weeks or by 5 fractions in 5 days followed by gap of 3 weeks followed by 5 fractions in 5 days are equally effective in LAHNC for palliative radiotherapy. Hence, to decrease the patient load in tertiary care institutes, it is recommended to use fractionation schedule with two radiotherapy fractions per week. ${ }^{11,12}$

\section{Acknowledgements}

None.

\section{Conflict of interest}

Author declares that there is no conflict of interest

\section{References}

1. Ferlay J, Soerjomataram I, Dikshit R, et al. Cancer incidence and mortality worldwide: sources, methods and major patterns in GLOBOCAN 2012. Int $J$ Cancer. 2015;136(5):E359-86.

2. Lamont EB, Vokes EE. Chemotherapy in the management of squamouscell carcinoma of the head and neck. Lancet Oncology. 2001;2:261-269.

3. Stupp R, Weichselbaum RR, Vokes EE. Combined modality therapy of head and neck cancer. Semin Oncol. 1994;21(3):349-58.

4. Soni A, Kaushal V, Verma M, et al. Comparative Evaluation of Three Palliative Radiotherapy Schedules in Locally Advanced Head and Neck Cancer. World Journal of Oncology. 2017;8(1):7-14.
5. Edge SB, Compton CC. The American Joint Committee on Cancer: the 7th edition of the AJCC cancer staging manual and the future of TNM. Ann Surg Oncol. 2010;17(6):1471-4.

6. De Jager R, Longeval E, Klastersky J. High-dose cisplatin with fluid and mannitol-induced diuresis in advanced lung cancer: a phase II clinical trial of the EORTC Lung Cancer Working Party (Belgium). Cancer Treat Rep. 1980;64(12):1341-6.

7. Mohanti BK, Umapathy H, Bahadur S, et al. Short course palliative radiotherapy of 20Gy in 5 fractions for advanced and incurable head and neck cancer: AIIMS study. Radiother Oncol. 2004;71(3):275-80.

8. Agarwal JP, Nemade B, Murthy V, et al. Hypofractionated palliative radiotherapy for advanced head and neck cancer. Radiother Oncol. 2008;89(1):51-6.

9. Das S, Thomas S, Pal SK, et al. Hypofractionated Palliative Radiotherapy in Locally Advanced Inoperable Head and Neck Cancer: CMC Vellore Experience. Indian J Palliat Care. 2013;19(2):93-8.

10. Kancherla KN, Oksuz DC, Prestwich RJ, et al. The role of split-course hypofractionated palliative radiotherapy in head and neck cancer. Clin Oncol (R Coll Radiol). 2011;23(2):141-8.

11. Cox JD, Stetz J, Pajak TF. Toxicity criteria of the Radiation Therapy Oncology Group (RTOG) and the European Organization for Research and Treatment of Cancer (EORTC). Int $J$ Radiat Oncol Biol Phys. 1995;31(5):1341-6.

12. Dhull AK, Atri R, Kaushal V. Alcohol as a risk factor in HNC, an enormous toll on the lines and communities. $J$ Evid Based Med Health. 2016;3:354-60. 